\title{
BARD
}

FINAL REPORT

PROJECT No. I-17-79

Some Dynamic Aspects of Technological Change in Agriculture

Y. Kislev, V.W. Ruttan, W. Peterson 
SOME DYNAMIC ASPECTS OF TECHNOLOGICAL

CHANGE IN AGRICULTURE

A Report to BARD 
BARD

P.0.Box 6,

Bet-Dagan, ISRAEL

BARD Proposal \# 1-17-79

Title of Research:

Principal Investigator:
Some Dynamic Aspects of Technological Change in Agricul tore

Yoav Kislev

Cooperating Investigator: Vernon $W$. Rutan and Willis Peterson

Name and Address of Affiliated Institutions:

Principal Institution:

Cooperating Institution:

Project's Commencement Date: 22 Oct., 1979

Type of Report:
The Center for Agricultural Economic Research P.0.Box 12, Rehovot; Israel

University of Minnesota,

Minneapolis, MN. 55101, USA

Final Scientific Report.

$\frac{\text { Teaplisi }}{\text { Principal Investigator }}$

$\frac{\text { Nita sade }}{\text { Institutiongathorizing official }}$ 
Overview

Prices, technology and Farm Size

Induced Innovations and Farm Mechanization

The Cotton Picker in Retrospect: Labor Displacement or Replacement Production Uncertainty; Risk and Economic Selection

Average and Variance in Wheat Yields

Farmers' Financing of Agricultural Research in Israel

Cooperation in the Moshav

Recent Inflationary Experience in Israel

Capital Intensity and Product Composition in the Kibbutz and the Moshav in Israel

Structural Changes in the Vegetable Industry in Israel

Supply of Fresh Beef from the Beef Herd in Israel

Cost of Yamit Settlement Project 
Several aspects of the adjustment of agriculture to technical change were studied in the Project.

A theory explaining growth of farm size as a reaction to rise in wages relative to cost of capital services was formulated and tested with American data. The capital cost measure adopted was custom rates and it was found to have a downward moving trend for the modern period, unlike other, possibly biased, measures. The same conceptual approach was carried over to a study of the cotton industry in which preliminary findings indicate that the major cause of the shift to machine picking was a reduction in labor supply as workers moved to better opportunities in town. Labor was thus mostly not pushed away by machines, but rather attracted away.

A theoretical model of an abstract industrial structure with stochastic production was developed. In an empirical study of related issues, the riskiness of new wheat varieties was tested and found not to be significantly higher than that of old types.

Financial problems were studied both at the farm cooperative level and the national level (inflation).

Several subjects were studied in relation to structural problems associated with technical changes. Among them: vegetable production in the family farm and the large farm, product composition in the kibbutz and the moshav, productivity differences in beef herds, and the experience accumulated in a new regional settlement project. 


\section{AN OVERVIEW}

The central purpose of the research project summarized in this Report was to clarify the dynamic processes affecting agriculture in a modern economy as technology improves--on the farm and in the economy at large. The basic hypothesis of the study was that technological developments cause changes in farm structure.

The Report consists of the collection of 12 papers dealing with various aspects of the issues raised. The papers are grouped into 4 subject categories and discussed in the first 4 sections of this Overview. Several of the papers were written as journal articles, others are shorter reports. Part of the work covered in this Report was done before the commencement of the reported Project but was completed with the aid of BARD's grant. Similarly, some of the studies opened in this Project wi.1 be completed in the next.

Wherever possible, the Report was written in non-technical terms to facilitate exposition to a wide audience. This is particularly true for the Overview. 


\section{Farm Size, Capital Labor Ratio and the Farm}

\section{Labor Force}

Technological improvements increase productivity and expand supply. As terms of trade turn against agriculture, some farmers leave and the agricultural labor force declines in size. This process is perhaps the most conspicuous manifastation of technological change in agriculture. It has long been recognized and described in terms of "shifts of the production function on the farm" and the resulting fact that fewer farmers can in modern times produce food for a larger population than was the case in the past. The growth of the individual production unit in agriculture, also typical of the process of modernization, was explained as a realization of economies of scale at the farm level.

In the first chapter of our study (Prices, Technology and Farm Size) we forward a theory that explains growth of farm units and increased capital labor ratio on farms as a rational economic reaction of farmers to increased urban income comparatively to the cost of capital services. The farmer increases the resources at his command to achieve parity income as urban earnings rise. For this process to take place, productivity on the farm ("shifts" of the farm production function) need not occure. Thus it is productivity in town, in manufacturing and services, which is a major driving force behind the growth of the farm unit. With limited markets and resources, growth of the farm unit means a decline in the number of farmers and in the size of the 1 abor force. 
The farm size theory is based in its basic formulation on the assumption of a constant amount of labor input per farm unit. Indeed, average farm labor input in the US has been virtually constant for several decades. This constancy is a manifestation of the structural strength of the American family farm. It was taken in our work as a basic assumption to start from. The challenge of explaining the phenomenon of constant labor input per farm and hence explaining the strength of the family unit is left to another occasion.

One of the more influential studies connecting increased capital labor ratio to on farm technological change was Binswanger's work on induced innovations in agriculture. In the second paper (Induced Innovations and Farm Mechanization) we argue that this empirical analysis was based on inappropriate measures of the cost of capital, particularly machinery. Binswanger's work was an attempt to explain capital deepening in face of allegedly increasing capital cost. If our measure of custom rates is accepted, the cost of capital services is seen to have declined and capital deepening can be explained, as we did, in terms of labor substitution. Resort to on farm technical change, to unexplained improvements in production ability, is simply not necessary.

Structural changes are often associated with human suffering. In particular, attention has been drawn to the displaced farm 1 abor force. A major study of this issue is Day's who argued, convincingly it seems, that the introduction of mechanization into cotton cultivation in the 
South was the reason for outmigation of farm laborers. In the third paper (The Cotton Picker in Retrospect: Labor Displacement or Replacement?) we consider the question of hand picking and machine harvesting of cotton. Our findings thus far show that the shift from hand picking to machine harvesting in cotton is mainly a shift in labor supply away from the cotton growing industry and not in labor demand. Consistently with the theory of farm size, we find here again that increasing outside apportunities caused labor exit and adoption of new technologies in agriculture.

2. Research, Technology and Risk

Increased productivity, expanded supply,worsening terms of trade and larger units of production narrow profit margines and increase economic risk in agriculture.

The theoretical paper on Production Uncertainty, Risk and Economic Selection views industry as a collection of enterpreneurs of differing ability and production as a stochastic process. Lines of production differ in riskiness. Market forces create a selection environment in which entrepreneurs are directed to production activities according to their comparative advantage in dealing with risk. In the resulting equilibrium, the risky lines of production may project a false immage of low risk activities due to their being run by the comparatively skilled operators. In part, the processes formulated in the essay explain the growing phenomenon of specialization in agriculture. 
In associating risk with technology, economists often think on subjective risk of new, unfamiliar technologies. However, new technologies can also be objectively more risky as often they imply higher levels of stress in animals or higher sensitivity to environmental conditions in plants. The paper on Average and Variance in Wheat Yields reports an examination of the issue of technology and risk in the relatively narrow framework of wheat varieties. The question posed was whether new varieties are more risky than the old types they replaced. For the limited data available in Israel it was found that economic risk does not change systematically with vintage of variety. It may be a reflection of the breeders' explicit attempt not to release for commercial use varieties they regard as unstable.

Wheat varieties are created by the research system and adopted by the farmers. As a side issue we raised the question of the influence farmers have on the research establishment. In the paper on Farmers' Financing of Agricultural Research in Israel we report that farmers make use of their financial leverage to direct research activity to. pressing, short term problems.

\section{Finance}

Ultimately, economic risk is risk of default--farmers losing in agriculture have to exit and turn to alternative pursuits. Financial institutions cushion against defaults; without them even temporary difficulties could have resulted in complete failure. We studied one aspect of finance, in Cooperative in the Moshav 
in Israel. We found that moshavim in which cooperation was strong were more successful than others in mobilizing financial resources--for investment and short term credit--to their members. As financial expansion increases capital labor ratio on farms, and the last enhances cooperation, cooperation and finance reinforce each other. We attempted to analyze the stability of this mutual relationship. Our main finding is that a moshav is stable even with partial cooperation.

The financial operation of the moshav was studied in an environment in which the government supported agriculture through subsidizing factors, products and credit. The involvement of government in economic activity in Israel is one reason for high rates of inflation which prevailed recently. Inflation affects agriculture in more than one way: it erades the value of credit, it changes terms of trade, it affects the exchange rate, it forces the government to take measures which interfere with efficient operation of the economy. We devoted one study to Recent Inflationary Experience in Israel. Among the conclusions drawn from the study: the demand, often heared in farm quarters, to accelerate the develuation of Israel's currency will be counter productive as i.t will eventually increase local prices at an even faster rate and eliminate any gains to the terms of trade of agriculture which may be expected at the first instance of devaluation. (More recently, in the fall of 1982, the government adopted a policy of delayed devaluation which is also counterproductive. But this experience occured after the completion of our study.) 


\section{Structural Issues}

Agriculture is often devided to sub-sectors--in Israel, to the kibbutz and the family farm. Examination of patterns of production reveal destinct differences between the composition of products in each of these sectors. The paper on Capital Intensity and Product Composition in the Kibbutz and the Moshav in Israel discusses the question of the separation of the difference in capital labor ratio in the kibbutz and the moshav to the part due to different composition of products and to the part due to different technoloies in the production of the same product.

Another paper, Structural Changes in the Vegetable Industry in Israe1, examines the devision of production in the vegetable industry between the family farm and the large farm according to lines of comparative advantages. The study also explains another phenomenon--the fact that despite the moshav's original adherence to the doctrine of self labor, most vegetable production in the moshav is done now with the help of hired labor. In the study we show that, while in the early 1960's a farmer could reach parity income growing vegetables solely with family labor, he could not do so in the late 1970's. The spread of hired labor in vegetable production, mostly unskilled and lower paid, expanded supply and lowered prices. As a result, to reach appropriate income levels, a vegetable producer must now control wide scale operations with large numbers of hired laborers. Those who keep to the original ideological position and maintein the doctrine of self labor turn to alternative lines of production--in agriculture or elsewhere. 
An important structural issue is the question of the differences in productivity between operators. This issue was studied in the Supply of liresh Beef from Beef Herds in Israel, which focused on differences in cost of beef production between the herds. The differences were found to be substential and a significant share of the industry will have to close down in lower prices. Supply will thus be cartailed. It was also found that, here too, finance was instrumental in explaining patterns of production: credit subsidies enabled many of the herds to continue in their operation despite relatively poor economic performance.

We conclude our Report with a survey of the Cost of Yamit Settlement Project in Northern Sinai. Public investment in agricultural settlement affected in the past and still affect today the structure of the production units for many years from their establishment and on.

\section{Further Work}

The work on the studies summarized in this Report continues with the support of our second BARD Project on Economic Development and the Changing Structure of the Family Farm.

Work on capital-labor ratio; mechanization and outmigration from agriculture in the US continues in two lines: a. further econometric timeseries analysis of the labor market for hand picking of cotton; b. a study of capital labor substitution at the regional level. 
In Israel, most attention is now given to the completion of a data set on the family farms. The set will include, for each of the same sample of 562 farms, Census files from the 1971 and 1981 Censuses and much more detailed information on production activities for 1975 and 1976. The completion of this set was delayed due to difficulties in identification of the sample farms in the Census data. The empirical work already commenced on this data set has been mainly production function estimates with particular attention to productivity differences between farms.

6. Measurements

1 dunam $=0.1$ hectare

1 shekel (IS) $=10$ Lira (IL)

\begin{tabular}{lcc} 
& $\begin{array}{c}\text { Inflation } \\
\text { (Change in consumer price } \\
\text { index during the year) }\end{array}$ & $\begin{array}{c}\text { Exchange Rate } \\
\text { (Average,1 Sheke1 } \\
\text { per US dollar) }\end{array}$ \\
\cline { 2 - 3 } 1975 & 39.3 & 0.63 \\
1976 & 31.3 & 0.79 \\
1977 & 34.6 & 1.05 \\
1978 & 50.6 & 1.7 \\
1979 & 78.3 & 2.5 \\
1980 & 131.0 & 5.1 \\
1981 & 116.8 & 11.4 \\
1982 & 131.9 & 24.3
\end{tabular}

An agricultural year in Israel: October-September. (1975, for example, is from October $1 ; 1.974$ to September 30,1975$)$. 


\section{Cooperation}

US-Israel cooperation on this Project was realized mostly in two facets of the Project.

a. Several of the studies were conducted together, as indicated by authorship;

b. Ideas were exchanged, in particular the conceptual approach to the farm size issue as an economic response to market signals--to wage rental ratio--first developed with respect to American agriculture, has been applied to the analysis of the development of agriculture in Israel.

\section{Publications of Studies Reported}

Kislev, Yoav and Willis Peterson, "Prices, Technology and Farm Size," Journal of Political Economy, 1982, 90 : 578-595.

Kislev, Yoav and Willis Peterson, "Induced Innovations and Farm Mechanization," American Journal of Agricultural Economics, $1981,63: 562-565$.

Kislev, Yoav and Yakir Plessner, "Inflation and the Rate of Exchange - A Monetary Interpretation" Economic Quarterly (Hebrew), 1981, 137-155.

Kislev, Yoav and Nava Haruvi, "Cooperation in the Moshav," Journal of Comparative Economics (forthcoming).

Kislev, Yoav and Ehud Gelb, "Farmers Financing of Agricultural Research in Israel," Research Policy, 1982, 321-327.

9. Award "Price, Technology and Farm Size", Honorable Mention, Quality of Research Discovery, American Agricultural Economic Association, 1983. 
10. Theses Included in the Report

Doctoral

Nava Haruvi - Cooperation in the Moshav

Master

Yaakov Gal - Average and Variance in Wheat Yields

Ehud Gelb - Farmers' Financing of Agricultural Research in Israel

Shlomit Farbstein - Capital Intensity and Product Composition in the Kibbutz and the Moshav in Israel

Arik Baruchin - Structural Changes in the Vegetable Industry in Israel Gerald Stoch - Supply of Fresh Beef from Beef Herds in Israel Ilan Be'eri - Cost of Yamit Settlement Project. 

